\title{
Retrieval of stratospheric aerosol size information from OSIRIS limb scattered sunlight spectra
}

\author{
A. E. Bourassa ${ }^{1,2}$, D. A. Degenstein ${ }^{2}$, and E. J. Llewellyn ${ }^{2}$ \\ ${ }^{1}$ Science Systems and Applications, Inc., Hampton, VA \\ ${ }^{2}$ Institute of Space and Atmospheric Studies, University of Saskatchewan, Saskatoon, SK \\ Received: 5 December 2007 - Published in Atmos. Chem. Phys. Discuss.: 26 February 2008 \\ Revised: 27 August 2008 - Accepted: 22 September 2008 - Published: 6 November 2008
}

\begin{abstract}
Recent work has shown that the retrieval of stratospheric aerosol vertical profiles is possible using limb scattered sunlight measurements at optical wavelengths. The aerosol number density profile is retrieved for an assumed particle size distribution and composition. This result can be used to derive the extinction at the measured wavelength. However, large systematic error can result from the uncertainty in the assumed size distribution when the result is used to estimate the extinction at other wavelengths. It is shown in this work that the addition of information obtained from the near infrared limb radiance profile at $1530 \mathrm{~nm}$ measured by the imaging module of the OSIRIS instrument yields an indication of the aerosol size distribution profile that can be used to improve the fidelity of the retrievals. A comparison of the estimated extinction profile at $1020 \mathrm{~nm}$ with two coincident occultation measurements demonstrates agreement to within approximately $15 \%$ from 12 to $27 \mathrm{~km}$ altitude.
\end{abstract}

\section{Introduction}

The retrieval of the vertical profile of stratospheric aerosol from limb scatter measurements is of recent interest for the continuation of the long term trend measurements made by past occultation experiments, including the Stratospheric Aerosol and Gas Experiment (SAGE) series (McCormick et al., 1979; Russell and McCormick, 1989; Thomason and Taha, 2003), the Halogen Occultation Experiment (Russell et al., 1993), and the Polar Ozone and Aerosol Measurement (POAM) II and III instruments (Glaccum et al., 1996; Lucke et al., 1999). Additionally, aerosol distributions have been used previously to study the dynamics of the tropical stratospheric reservoir and stratospheric circulation patterns

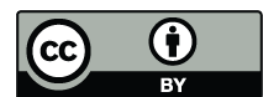

Correspondence to: A. E. Bourassa (adam_bourassa@usask.ca)
(Grant et al., 1996; Trepte and Hitchman, 1992), and the relatively high global and vertical resolution measurements possible with the limb scatter technique have potential to further such studies. Furthermore, since uncertainty in stratospheric aerosol is one of the dominant error sources in the retrieval of ozone from limb scatter (Loughman et al., 2005) the ability to retrieve aerosol directly from the measurements is critical to minimize this impact.

Previous studies have shown the potential for the retrieval of stratospheric aerosol parameters from limb scattered radiance profiles. These include methods proposed by Tukiainen et al. (2008), which retrieves an aerosol number density from OSIRIS radiances using a Modified Onion Peel technique and parameterizations of the cross sections and scattering phase functions, and by Rault and Loughman (2007), which uses an optimal estimation technique and Mie scattering phase functions to retrieve multichannel extinction profiles from SAGE III limb scatter measurements.

The work focuses on another technique recently presented by Bourassa et al. (2007) for the retrieval of the stratospheric aerosol number density profile from limb scatter sunlight spectra. This technique uses limb radiance profiles at $470 \mathrm{~nm}$ and $750 \mathrm{~nm}$ measured by the Optical Spectrograph and InfraRed Imaging System (OSIRIS) satellite instrument (Llewellyn et al., 2004). The inversion, which is performed using a Multiplicative Algebraic Reconstruction Technique (MART), retrieves the aerosol number density profile for an assumed particle size distribution and composition. Stratospheric sulphate aerosols are incorporated into the radiative transfer model (Bourassa et al., 2008) as scattering and absorbing particles, with cross sections and scattering phase function calculated with a standard Mie code (Wiscombe, 1980) and an index of refraction for hydrated sulphuric acid tabulated as a function of wavelength (Palmer and Williams, 1975). The measurement vector is taken as the logarithm of the ratio of the $750 \mathrm{~nm}$ radiance to the $470 \mathrm{~nm}$ radiance. Bourassa et al. (2007) show that the extinction derived from

Published by Copernicus Publications on behalf of the European Geosciences Union. 

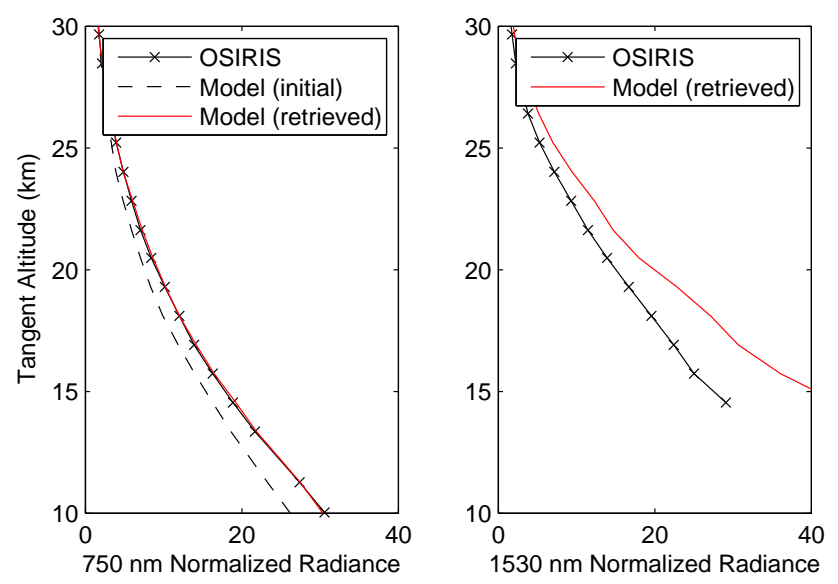

Fig. 1. Modelled and measured limb radiance spectra (normalized to $31 \mathrm{~km}$ ) using the initial guess and retrieved aerosol number density profile assuming a uniform height profile of size distribution parameters (mode radius of 0.15 micron, mode width of 1.6).

the retrieved density and the scattering cross section, which is calculated using Mie theory for the assumed size distribution, is sensitive to uncertainty in the size distribution. At $750 \mathrm{~nm}$, the sensitivity is small as it arises only from error in the scattering phase function; however, when the result is used to extrapolate the extinction to other wavelengths, the uncertainty in the size distribution leads to large systematic error. Typically, the effects of forward model parameter errors, such as uncertainty in the neutral density and albedo, are small compared to the uncertainty that arises from the assumed particle size. For the full error analysis see Bourassa et al. (2007).

Many other studies have shown that it is possible to retrieve aerosol particle size information from multi-spectral measurements of the extinction (e.g. Ångström, 1929; Wang et al., 1989; Bingen et al., 2004). In this paper, we show that the same retrieval technique Bourassa et al. (2007) apply at $750 \mathrm{~nm}$ can be applied to the limb radiance profile at $1530 \mathrm{~nm}$ that is measured by one of the channels of the InfraRed Imaging (IRI) module of OSIRIS. In combination, these two results yield an indication of the particle size distribution that is used to improve the fidelity of the retrieved number density and greatly minimize the systematic error in the estimate of the aerosol extinction across the spectrum.

\section{IRI measurements}

The three channels of the IRI subsection of the OSIRIS instrument provide vertical images of the band integrated 1260 , 1270 and $1530 \mathrm{~nm}$ atmospheric limb radiance. The 1260 and $1270 \mathrm{~nm}$ channels are designed to measure a molecular emission from excited state molecular oxygen that is formed through ozone photo-dissociation. This emission is quite bright compared to the Rayleigh background and so makes these channels useless for the characterization of scattered sunlight. The $1530 \mathrm{~nm}$ channel is designed to measure the hydroxyl Meinel band emission that is also related to ozone photo-chemistry. However, this emission is extremely weak during the daytime and so results in measurements of limb scattered sunlight that are not significantly contaminated by the $\mathrm{OH}$ emission.

The IRI measurements are inherently different from the Optical Spectrograph (OS) measurements in that the IRI takes a multi-pixel vertical image of the limb, at a vertical resolution of approximately $1 \mathrm{~km}$, with every exposure. The OS has a single line of sight and so requires the satellite to nod to accomplish a vertical limb scan. The optical axis of the OS and the IRI are co-aligned such that the pixel corresponding to the optical axis of the IRI has the same line of sight as the OS. Therefore, the OS and IRI are best used in combination by using measurements from the optical axis pixel of the IRI over the course of a vertical scan of the OS line of sight rather than an entire IRI vertical image from a single exposure. However, as the exposures of the OS and the IRI are not synchronized, a simple log-space linear interpolation of the IRI radiance profile to the OS tangent altitudes is required for the retrieval.

\section{Size information}

Bourassa et al. (2007) show comparisons of the OS measurements with forward model radiances calculated using the retrieved aerosol number density profile and the assumed size distribution. The good agreement that is demonstrated at all wavelengths from 470 to $810 \mathrm{~nm}$ suggests that there is little, or no, further information in the OS spectra that can be used to infer particle size. Similar agreement is obtained for any reasonable choice of size distribution. However, when the retrieved aerosol profile is used to forward model the limb radiance in the near infrared at $1530 \mathrm{~nm}$, there is a significant difference between the modeled radiance and the IRI measurement. This discrepancy is an indication of the error in the assumed particle size distribution.

Figure 1 is a plot of the limb radiance measured by the OS at $750 \mathrm{~nm}$ and by the IRI at $1530 \mathrm{~nm}$ during scan 15616043 . The IRI profile is taken from the optical axis pixel and interpolated to the OS tangent altitudes. Forward model radiances calculated using the SASKTRAN spherical, successive orders radiative transfer model (Bourassa et al., 2008) with five orders of multiple scattering are also shown in the figure. All profiles are normalized to the radiance at $31 \mathrm{~km}$ tangent altitude because the absolute calibration of the IRI is uncertain. The left panel shows the modeled radiance profile at $750 \mathrm{~nm}$ using the initial guess aerosol number density profile and the retrieved profile using the $750 \mathrm{~nm} / 470 \mathrm{~nm}$ ratio measurement vector. The right panel shows the model result at $1530 \mathrm{~nm}$, again using the same retrieved aerosol number density profile. 
The size distribution assumed for this retrieval is lognormal (Hansen and Travis, 1974), and constant in altitude, with a mode radius of 0.15 micron and a mode width of 1.6. This mode radius is approximately a factor of two larger than that expected for typical background conditions (Deshler et al., 2003), and was chosen to demonstrate the sensitivity to the size distribution.

The radiance profiles at $750 \mathrm{~nm}$ demonstrate good agreement between the measurement and the model calculation that uses the retrieved aerosol profile. However, the modeled radiance at $1530 \mathrm{~nm}$ is systematically higher than the IRI measurement at all altitudes. This bias is due to error in the assumed particle size. The Ångström relation (Ångström, 1964) approximates the aerosol scattering cross section by a simple inverse power law where the wavelength dependence for large particles is weaker than that for small particles. In a single scatter sense, the systematically high radiance predicted by SASKTRAN at $1530 \mathrm{~nm}$ in Fig. 1 is due to an aerosol scattering cross section that is too large. Thus, using the Ångström exponent relation, this can be interpreted as a size distribution corresponding to particles that are too large; that is, in order to make the $1530 \mathrm{~nm}$ model prediction agree with the IRI measurements, the aerosol cross section must decrease more quickly with wavelength. Therefore the IRI observations provide a measured sensitivity to the aerosol particle size distribution parameters. It is important to note that this is not strictly the case as the single scatter radiance is in fact proportional to the product of the cross section and the phase function, both of which are function of the particle size distribution. However, for the wavelengths and particle sizes of interest here, the phase function varies relatively slowly with particle size (McLinden et al., 1999).

\section{Methodology}

The aerosol number density retrieval described by Bourassa et al. (2007) characterizes the aerosol scattering with a measurement vector that is constructed using the logarithm of the ratio of the radiance at a long wavelength to the radiance at a shorter wavelength (in this case $750 \mathrm{~nm}$ to $470 \mathrm{~nm}$ ). The inversion fits the model prediction to the measurement by adjusting the aerosol number density in a manner that is consistent at both the long and short wavelengths. Choosing a different combination of wavelengths to form the measurement vector ratio yields a retrieved number density that is radiatively consistent with this alternate set of wavelengths. If the assumed particle size distribution accurately describes the actual size distribution, the retrieved number density does not depend on the choice of different wavelength pairs, i.e. any wavelength ratio with sufficient sensitivity will yield the same retrieved number density. However, if the assumed size distribution does not accurately describe the real distribution, the retrieved number density will differ in order to best match the measurement vector for the specific wavelength pair.
Consider the result of performing the aerosol number density retrieval several times, where each time the long wavelength of the ratio is shifted to a longer wavelength. Each of the retrieved number density profiles, $n_{i}(h)$, can be converted to extinction at each measured wavelength using the corresponding scattering cross section, $\sigma(\lambda, h)$. The effect of uncertainty in the assumed size distribution has only a small effect on the retrieved extinction due to error in the phase function used in forward model in the inversion (Bourassa et al., 2007). For each altitude, $h$, and for each wavelength, $\lambda_{i}$, the retrieved extinction is,

$k\left(\lambda_{i}, h\right)=\sigma\left(\lambda_{i}, h\right) n_{i}(h)$.

Choosing one of the measured extinction profiles as a reference yields a measured extinction ratio at each of the remaining wavelengths,

$\tilde{k}_{\text {meas }}\left(\lambda_{i}, h\right)=\frac{k\left(\lambda_{i}, h\right)}{k\left(\lambda_{\text {ref }}, h\right)}$.

Theoretically, the extinction ratio is simply the cross section ratio because the actual number density, which cannot depend on wavelength, cancels in the ratio,

$\tilde{k}_{\text {theory }}\left(\lambda_{i}, h\right)=\frac{\sigma\left(\lambda_{i}, h\right) n(h)}{\sigma\left(\lambda_{\text {ref }}, h\right) n(h)}=\tilde{\sigma}\left(\lambda_{i}, h\right)$.

Therefore, the problem reduces to a standard minimization. Using the set of retrieved number density profiles, one for each wavelength, a set of measured extinction ratios is determined (this will be one less than the number of wavelengths as one is the reference). Using Mie theory, the extinction ratio can be calculated as the cross section ratio at each measured wavelength for any size distribution. Assuming a single mode log-normal distribution reduces the problem to the determination of the mode radius and the mode width that correspond to a set of extinction ratios that best match the measured extinction ratios.

\section{Implementation with OSIRIS}

Assuming the log-normal size distribution parameters used to perform the aerosol inversion shown in Sect. 3, the aerosol number density inversion was performed a second time on scan 15616043 using the $1530 \mathrm{~nm}$ imager radiance profile for the long wavelength channel. As expected, due to the uncertainty in the assumed size distribution, the two inversions yield different retrieved number density profiles. These two profiles, and the initial guess profile, are shown in the left panel of Fig. 2. Since the assumed distribution is uniform in altitude, the resulting extinction at each wavelength, is simply a scaling of the retrieved number density by the corresponding scattering cross section. The calculated extinction ratio,

$\tilde{k}_{\text {meas }}(750 \mathrm{~nm}, h)=\frac{k(750 \mathrm{~nm}, h)}{k(1530 \mathrm{~nm}, h)}$, 

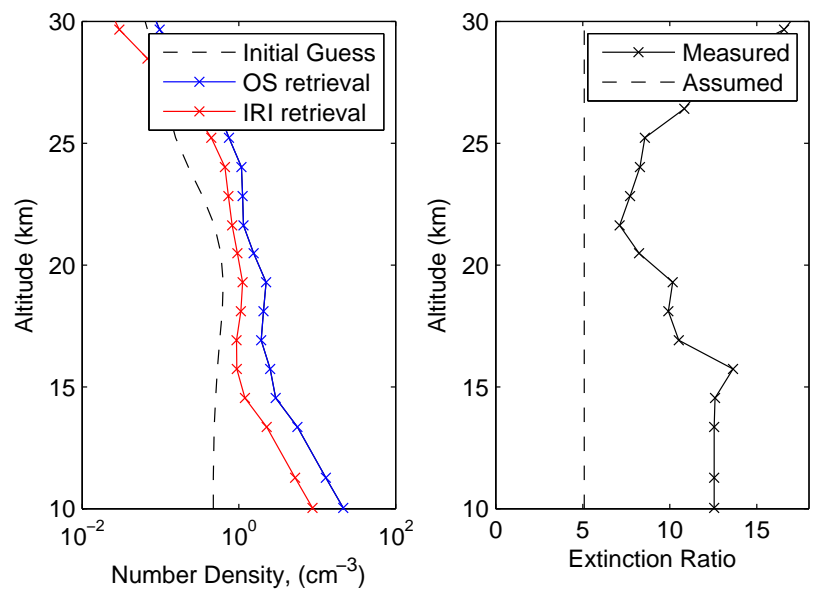

Fig. 2. The initial guess and retrieved aerosol density profiles obtained using the $750 \mathrm{~nm}$ (OS) and $1530 \mathrm{~nm}$ (IRI) channels, and the resulting extinction ratio.

is shown in the right panel of the figure along with the extinction ratio from the assumed size distribution. The shape of the extinction ratio profile reflects the shape of the particle size distribution profile in that a smaller extinction ratio corresponds to larger particle size.

The theoretical extinction ratio at these wavelengths can be pre-calculated using the Mie cross sections for a large set of log-normal mode radius and mode width values. The left panel of Fig. 3 shows the least-squares fit between the measured and theoretical extinction ratio at $18 \mathrm{~km}$ altitude. Blue in this standard colour scale denotes the value of zero. Clearly, this single measured extinction ratio does not provide a unique minimum in the least-square space. A family of solutions arise that show that for each mode width, there is a value of mode radius that corresponds to the extinction ratio that matches the measurement. The zero in the least squares space decreases in mode radius for increasing values of mode width. This is understandable as the distribution must widen as the radius decreases in order to maintain the same effective scattering cross section. This situation of a family of solutions is typical and a similar solution occurs at other altitudes in this scan. Optimistically, this result provides one of the two assumed parameters. For an assumed mode width, the mode radius is fixed; conversely, for an assumed mode radius, the mode width is fixed.

The right panel Fig. 3 shows the altitude profile of the mode radius that is determined from the least squares fit of the extinction ratio for an assumed mode width of 1.6 and a large range of pre-calculated mode radii. The retrieved particles sizes are smaller at all altitudes than the initial guess as predicted from inspection of the original modeled $1530 \mathrm{~nm}$ radiance profile. The value of mode width, 1.6, is somewhat arbitrary; however, it is consistent with the in-situ measurements made by Deshler et al. (2003).
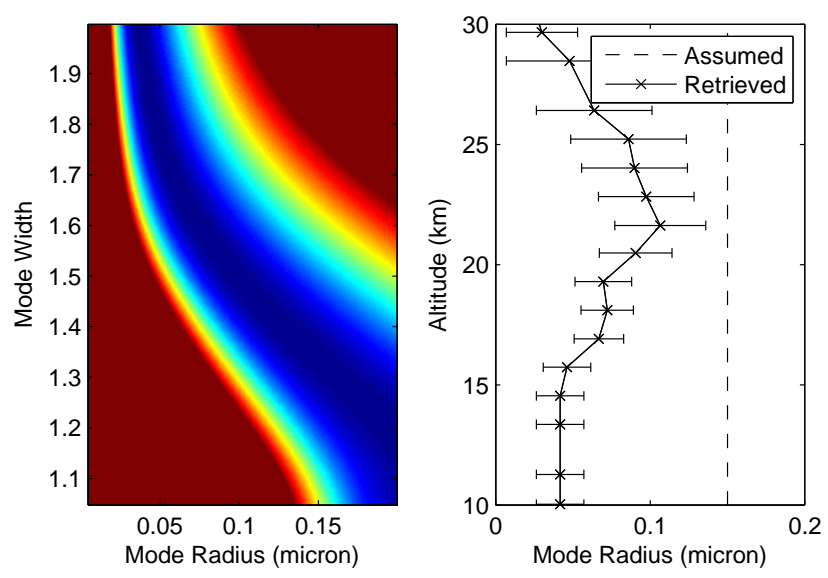

Fig. 3. Least squares fit values of log-normal size distribution parameters for the retrieved extinction ratio at $18 \mathrm{~km}$ altitude, and the retrieved mode radius profile for assumed mode width of 1.6.

The error bar shown on the mode radius values in Fig. 3 is a simple propagation of the aerosol number density error bar through the extinction ratio and least squares fit. It is quite large as it represents a worst case. The size of the error is partly due to the fact that the minimum in the least squares space is not narrow; for an assumed mode width, a relatively small change in the extinction ratio produces a large change in the mode radius. Thus detector noise, the dominant term in the error in the retrieved aerosol number density, creates a large error bar in mode radius.

It is generally true that the addition of the extinction ratio at more wavelengths should provide the ability to fix both size distribution parameters. This same method was applied to a set of retrieved extinction profiles at $700,750,800$ and $1530 \mathrm{~nm}$. Measurements at wavelengths shorter than $700 \mathrm{~nm}$ are significantly contaminated by the Chappuis ozone absorption band. The best fit size distribution parameters for the set can then be found by standard chi-squared minimization where $1530 \mathrm{~nm}$ is again used as the reference wavelength. It was found that the inclusion of the extinction at these additional wavelengths is unable to further determine the size distribution and almost identical results were found. This is due to the fact that the Mie scattering cross section curve is quite flat over the region from 700 to $800 \mathrm{~nm}$ and almost no extra information is gained by incorporating these measurements.

It is possible to iterate this number density/particle size procedure by using the retrieved size distribution profile to retrieve the extinction ratio again. This results in a second estimate of the size distribution profile. Errors due to uncertainty in the phase function should decrease with iteration. However, the iteration is very sensitive to structure in the size distribution profile and because the error bar is quite large, the noise quickly becomes unmanageable. Improvements to the technique are possible, such as forcing a smooth 
functional form for the size distribution profile or using a statistical inversion technique to create a weighted average with a smooth a priori state. However, for this study it is concluded that a first estimate of the mode radius for an assumed mode width is possible using the $750 \mathrm{~nm} / 1530 \mathrm{~nm}$ extinction ratio.

\section{Coincident SAGE II/III extinction}

The OSIRIS scan used in this work was chosen as it is a coincident measurement with SAGE II and SAGE III occultation events used by Bourassa et al. (2007). To derive the best estimate of the aerosol extinction profile, we use the retrieved mode radius profile shown in Fig. 3 with the assumed mode width of 1.6 , and retrieve the corresponding aerosol number density profile a final time using the standard $750 \mathrm{~nm} / 470 \mathrm{~nm}$ ratio. The result is converted to extinction at $1020 \mathrm{~nm}$ using the Mie scattering cross section corresponding to the retrieved size distribution at each altitude. The error bar in the figure reflects the uncertainty in the retrieval of the extinction The OSIRIS extinction profile is shown in Fig. 4, together with the coincident SAGE II and III measurements. The extinction derived from the aerosol number density inversion with the assumed size distribution profile is also shown. Clearly the OSIRIS extinction for the retrieved size profile is an improvement over the result derived for the assumed size. The OSIRIS profile agrees with the occultation measurements to within the error bar for most points between 12 and $27 \mathrm{~km}$. The error bar reflects the uncertainty derived from the number density inversion as derived in Bourassa et al. (2007). It is again important to note that the assumed mode radius used here was purposely chosen to be significantly larger than a typical background size in order to demonstrate the sensitivity to the assumed size and the improvement in the result that is possible when using the IRI measurement. It is also encouraging to note that the structure in the extinction profile for the assumed size profile is corrected when the retrieved size information is incorporated. This is due to the fact that the assumed size is constant in altitude and because the true profile is peaked, this structure is compensated for in the retrieved density.

\section{Conclusions}

While is it difficult to ascertain from this brief comparison a validation of the particle size information that can be obtained from the OSIRIS measurements, it is clear that by including the near infrared measurements an indication of the particle size distribution can be obtained. This distribution is typical of background conditions and yields good agreement in retrieved extinction at $1020 \mathrm{~nm}$ with the measurements from SAGE II and III. It should be noted that volcanically perturbed conditions present several challenges that

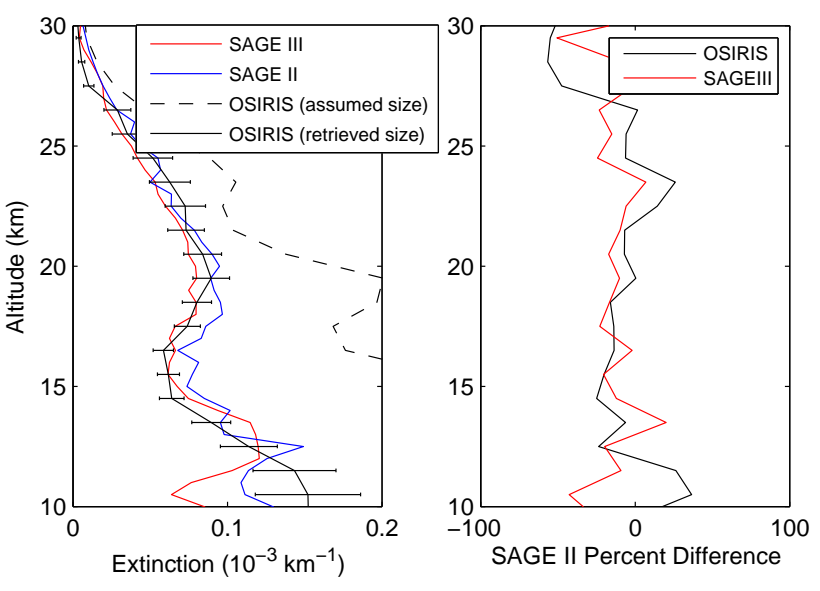

Fig. 4. SAGE II/III and OSIRIS intercomparison of $1020 \mathrm{~nm}$ extinction for the assumed size distribution profile and for the retrieved aerosol mode radius profile shown in Fig. 3. All profiles are interpolated to the same $1 \mathrm{~km}$ altitude grid.

may not be easily addressed given the assumptions inherent in this technique, such as a significant and potentially unknown change in the refractive index of the particles and multi-modal size distributions.

We believe that this work shows the potential for two significant advances. First, there is potential for the retrieval of height resolved global maps of the aerosol size distribution at the resolution possible with limb scatter measurements. Secondly, the ability of the limb scatter technique to infer the size distribution independently for the robust retrieval of aerosol extinction makes limb scatter measurements a realistic alternative for long term operational monitoring of the stratosphere.

Acknowledgements. This work is supported in part by the Canadian Space Agency.

Edited by: D. Cziczo

\section{References}

Ångström, A.: On the transmission of sun radiation and on dust in the air, Geogr. Ann., 2, 156-166, 1929.

Ångström, A.: The parameters of atmospheric turbidity, Tellus, 16, 64-75, 1964.

Bingen, C., Fussen, D., and Vanhellemont, F.: A global climatology of stratospheric aerosol size distribution parameters derived from SAGE II data over the period 1984-2000: 1. Methodology and climatological observations, J. Geophys. Res., 109, D06201, doi:10.1029/2003JD003518, 2004.

Bourassa, A. E., Degenstein, D. A., Gattinger, R. L., and Llewellyn, E. J.: Stratospheric aerosol retrieval with OSIRIS limb scatter measurements, J. Geophys. Res., 112, D10217, doi:10.1029/2006JD008079, 2007. 
Bourassa, A. E., Degenstein, D. A., and Llewellyn, E. J.: SASKTRAN: A spherical geometry radiative transfer code for efficient estimation of limb scattered sunlight, J. Quant. Spectrosc. Ra., 109, 52-73, 2008.

Deshler, T., Hervig, M. E., Hofmann, D. J., Rosen, J. M., and Liley, J. B.: Thirty years of in-situ stratospheric aerosol size distribution measurements from Laramie, Wyoming (41 N), using balloon-borne instruments, J. Geophys. Res., 108(D5), doi:10.1029/2002JD002514, 2003.

Glaccum, W., Lucke, R. L., Bevilacqua, R. M., Shettle, E. P., Hornstein, J. S., Chen, D. T., Lumpe, J. D., Krigman, S. S., Debrestian, D. J., Fromm, M. D., Dalaudier, F., Chassefière, E., Deniel, C., Randall, C. E., Rusch, D. W., Olivero, J. J., Brogniez, C., Lenoble, J., and Kremer, R.: The Polar Ozone and Aerosol Measurement instrument, J. Geophys. Res., 101, 14 479-14488, doi:10.1029/96JD00576, 1996.

Grant, W. B., Browell, E. V., Long, C. S., Stowe, L. L., Grainger, R. G., and Lambert, A.: Use of volcanic aerosols to study the tropical stratospheric reservoir, J. Geophys. Res., 101(D2), 3973-3988, doi:10.1029/95JD03164, 1996.

Hansen, J. E. and Travis, L. D.: Light scattering in planetary atmospheres, Space Sci. Rev., 16, 527-610, 1974.

Llewellyn, E. J., Lloyd, N. D., Degenstein, D. A., Gattinger, R. L., Petelina, S. V., Bourassa, A. E., Wiensz, J. T., Ivanov, E. V., McDade, I. C., Solheim, B. H., McConnell, J. C., Haley, C. S., von Savigny, C., Sioris, C. E., McLinden, C. A., Griffioen, E., Kaminski, J., Evans, W. F., Puckrin, E., Strong, K., Wehrle, V., Hum, R. H., Kendall, D. J. W., Matsushita, J., Murtagh, D. P., Brohede, S., Stegman, J., Witt, G., Barnes, G., Payne, W. F., Piché, L., Smith, K., Warshaw, G., Deslauniers, D.-L., Marchand, P., Richardson, E. H., King, R. A., Wevers, I., McCreath, W., Kyrölä, E., Oikarinen, L., Leppelmeier, G. W., Auvinen, H., Mégie, G., Hauchecorne, A., Lefèvre, F., de La Nöe, J., Ricaud, P., Frisk, U., Sjoberg, F., von Schéele, F., and Nordh, L.: The OSIRIS instrument on the Odin spacecraft, Can. J. Phys., 82, 411-422, 2004.

Loughman, R. P., Flittner, D. E., Herman, B. M., Bhartia, P. K., Hilsenrath, E., and McPeters, R. D.: Description and sensitivity analysis of a limb scattering ozone retrieval algorithm, J. Geophys. Res., 110, D19301, doi:10.1029/2004JD005429, 2005.
Lucke, R. L., Korwan, D. R., Bevilacqua, R. M., Hornstein, J. S., Shettle, E. P., Chen, D. T., Daehler, M., Lumpe, J. D., Fromm, M. D., Debrestian, D., Neff, B., Squire, M., König-Langlo, G., and Davies, J.: The Polar Ozone and Aerosol Measurement (POAM) III instrument and early validation results, J. Geophys. Res., 104, 18 785-18 800, doi:10.1029/1999JD900235, 1999.

McCormick, M. P., Hamill, P., Pepin, T. J., Chu, W. P., Swissler, T. J., and McMaster, L. R.: Satellite studies of the stratospheric aerosol., B. Am. Meteorol. Soc., 60, 1038-1047, 1979.

McLinden, C. A., McConnell, J. C., McElroy, C. T., and Griffioen, E.: Observations of stratospheric aerosol using CPFM polarized limb radiances., J. Atmos. Sci., 56, 233-240, 1999.

Palmer, K. F. and Williams, D.: Optical constants of sulfuric acid Application to the clouds of Venus, Appl. Optics, 14, 208-219, 1975.

Rault, D. and Loughman, R.: Stratospheric and upper tropospheric aerosol retrieval from limb scatter signals, Proc. SPIE, 6745, 674509 pp., doi:10.1117/12.737325, 2007.

Russell, J. M., Gordley, L. L., Park, J. H., Drayson, S. R., Hesketh, W. D., Cicerone, R. J., Tuck, A. F., Frederick, J. E., Harries, J. E., and Crutzen, P. J.: The Halogen Occultation Experiment, J. Geophys. Res., 98, 10777-10 797, 1993.

Russell, P. B. and McCormick, M. P.: SAGE II aerosol data validation and initial data use: An introduction and overview, J. Geophys. Res., 94, 8335-8338, 1989.

Thomason, L. W. and Taha, G.: SAGE III aerosol extinction measurements: Initial results, Geophys. Res. Lett., 30(12), 1631, doi:10.1029/2003GL017317, 2003.

Trepte, C. R. and Hitchman, M. H.: Tropical stratospheric circulation deduced from satellite aerosol data, Nature, 355, 626-628, 1992.

Tukiainen, S., Hassinen, S., Seppala, A., Auvinen, H., Kyrola, E., Tamminen, J., Haley, C., Lloyd, N., and Verronen, P.: Description and validation of a limb scatter retrieval method for Odin/OSIRIS, J. Geophys. Res., 113, D04 308, doi:10.1029/2007JD008591, 2008.

Wang, P.-H., McCormick, M. P., Fuller, W. H., Yue, G. K., Swissler, T. J., and Osborn, M. T.: Inference of stratospheric aerosol composition and size distribution from SAGE II satellite measurements, J. Geophys. Res., 94, 8435-8446, 1989.

Wiscombe, W. J.: Improved Mie scattering algorithms, Appl. Optics, 19, 1505-1509, 1980. 